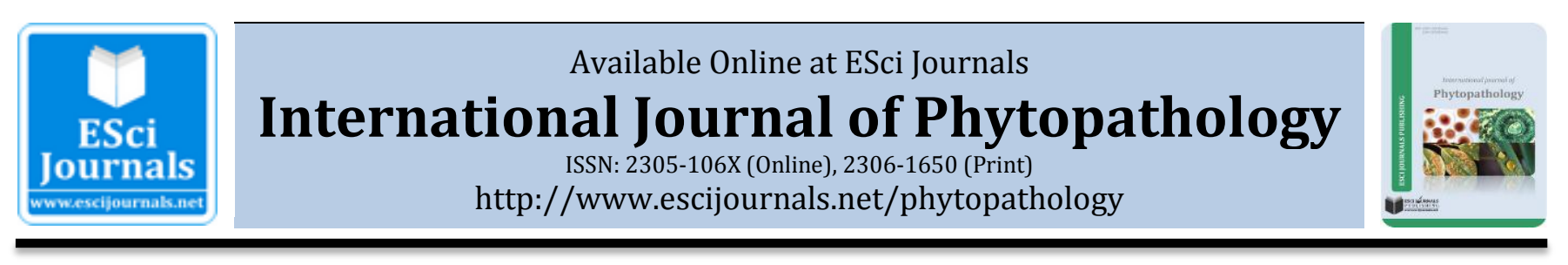

\title{
PHYTOCHEMICAL COMPOSITION, ANTIMICROBIAL EFFECT OF AZADIRACHTA INDICA AND CARICA PAPAYA EXTRACTS ON FUNGI ISOLATED FROM GMELINA ARBOREA SEEDLINGS
}

\author{
aUmana E. Johnson, aPatrick I. Akwaji*, aMarkson Aniedi-Abasi, bUdo S. Effiong, aOrok E. Effiom \\ a Department of Botany, University of Calabar, Calabar, Nigeria. \\ ${ }^{b}$ Department of Biological Sciences, Cross River University of Technology, Calabar, Nigeria.
}

\begin{abstract}
A B S T R A C T
Gmelina arborea Roxb has important economic value in Nigeria and worldwide. It has been used as timber, for pulp and paper, furniture, plywood and for particle board. Due to the menace caused by fungal diseases in nurseries and sites where the seedlings are raised and the observed disease severity at the Awi Gmelina Forestry Project Nursery in Cross River State, Nigeria. It became necessary to provide a viable environmentally friendly measure to curb the diseases, hence, a trial on the antifungal effects of leaf extracts of Carica papaya and Azadirachta indica in-vitro using different extract solvents on some pathogenic fungi isolated from Gmelina arborea seedlings. The isolated fungi were Trichoderma viride (from stem and leaf) and Mucor mucedo (stem and leaf). The solvents used were ethanol, methanol, propanol, butanol, acetone, chloroform and distilled water. Phytochemical screening of extracts of C. papaya from the different solvents showed that there was no tannin and hydroxymethyl anthraquinine. Flavonoids and polyphenols were in excess in acetone and methanol extracts respectively. For A. indica, polyphenols were only found in excess in ethanol and methanol extracts. Application of the extracts at different percentages of $0 \%$ (control), 10\%, 20\%, 30\%, $40 \%, 50 \%, 60 \%, 70 \%, 80 \%, 90 \%$ and $100 \%$ showed that Carica papaya extracted with butanol was more potent on Trichoderma viride and Mucor mucedo at 60\%, 70\%, 80\% and 100\% while the growth of Trichoderma viride and Mucor mucedo was checked by butanol extracts of A. indica at 70\%, 80\%, 90\% and $100 \%$. Conclusively, butanol extracts of C. papaya and A. indica at higher concentrations is recommended for use as spray to control the diseases.
\end{abstract}

Keywords: Plant extracts, extract solvents, concentration, antimicrobial effect, Gmelina arborea seedlings.

\section{INTRODUCTION}

Extract solvents have some effect on the potency of plant extracts. They either act by increasing or suppressing the toxicity of this point extracts (Onifade, 2000). Some of the extracts used in the extraction of plants are mainly organic solvents such as: chloroform, hexane, ethanol, butanol, petrol ether, acetone and water being the only inorganic solvent. Carica papaya and Azadirachta indica have medicinal properties which can be used in the control of some disease pathogens in both plants and animals. For instance, Carica papaya contains some phytochemical components such as alkaloids, glycosides, flavonoids and polyphenols in fruits and leaves which has antifungal and microbial effects (Mbadianya et al., 2013).

\section{* Corresponding Author:}

Email: akwajiisnever@yahoo.com

(c) 2014 ESci Journals Publishing. All rights reserved.
Azadirachta indica (neem plant) is referred to as a miracle tree because of the many goods and services it has provided mankind over thousands of years. It has many beneficial and insecticidal properties. The seed oil of this plant is used to treat skin diseases, tuberculosis and even used as hair tonic (Lauridsen and Kjaer, 2002). Gmelina arborea belongs to the family Verbanaceae. It was first introduced to Nigeria from Asia in 1917. Since then, it has remained important amongst the few tree species that are found in pure stand plantations in the country (Adegbehin et al., 1988, Epinoza, 2003). The wood of Gmelina is soft, light (though strong for its weight) and the color often is pale yellow to cream colored or plukish. It has been discovered to be good for pulp and paper and also for furniture, joinery, plywood and particle board production (Dvorak, 2003). There have been reports on attack of Gmelina plants by fungal 
pathogens (Duke, 2002). Most times, attack at the mature stage does not cause serious harm. Heavy damage has been reported at the seedling stage especially, under wet and hot weather. Because of the menace caused by fungal diseases in nurseries and sites where they are raised and the observed disease incidence/severity at the Awi Gmelina Forestry Project, and in view of the role played by this plant in the economy of Cross River State, Nigeria. It became necessary to isolate and identify the causative agents of the infection, to find out a better control measure that is environmentally friendly such as the use of plant extracts to control the infection.

\section{MATERIALS AND METHODS}

Sources of Materials: Diseased parts of Gmelina arborea seedlings (stem and leaves) were obtained from the Awi Gmelina Forestry Project in Akamkpa local Government Area of Cross River State, Nigeria and wrapped in sterile cellophane bags and transported to the Laboratory. Carica papaya and Azadirachta indica leaves were obtained from the Botanic Garden of the Department of Botany, University of Calabar, Calabar, Cross River state, Nigeria.

Source of Fungal Pathogens and Morphological Identification: The fungal pathogens used in this research work were isolated from diseased leaves and stems of Gmelina arborea seedlings collected from the Awi Gmelina Forestry Project at Akamkpa Local Government Area of Cross River State, Nigeria. Cut sections of the diseased assay plants were surface sterilized with $70 \%$ sodium hypochlorite (bleach) solution for $1 \mathrm{~min}$ and rinsed quickly in 3 changes of sterile distilled water, blotted dry on Whatman's No. 1filter paper and placed on Potato Dextrose Agar (PDA) in Petri dishes. Four (4) sections were inoculated per Petri dish. The plates were incubated at $28 \pm 1^{\circ} \mathrm{C}$ until fungal growth was noticed. After 5 days, the different isolates were subcultured on freshly prepared PDA to obtain their pure culture. Isolated fungi were microscopically (Olympus optical, Phillipines) identified as far as possible using the identification guides of the International Mycological Institute, Kew and of Barnett and Hunter (1998), Alexopolous and Mins (1989). Stock cultures of these fungi were stored in agar slant bottles for subsequent use.

Preparation of Extracts: Leaves of Carica papaya and Azadirachta indica obtained were washed with distilled water and oven dried at a temperature of $80^{\circ} \mathrm{C}$ for 24 hours, grounded into fine powder and extracted separately using $100 \mathrm{ml}$ of $95 \%$ concentration of ethanol, methanol, acetone, chloroform, propanol, butanol and distilled water.

Susceptibility Test: The extracts percentage concentrations were prepared at $10 \%, 20 \%, 30 \%, 40 \%$, $50 \%, 60 \%, 70 \%, 80 \%, 90 \%$ and $100 \%$ with different solvents of ethanol, methanol, acetone, chloroform, propanol, butanol and distilled water.

Dilution Test Procedure: $1 \mathrm{ml}$ of each concentration was first poured into different Petri dishes using sterile syringes. The sterilized Potato Dextrose Agar (PDA) was also poured into the plates containing the solvent extracts after which the plates were gently swirled to ensure mixing. The media was allowed to solidify and with a sterilized No. 2 cork borer of $5.5 \mathrm{~mm}$ in diameter, a disc of the matured culture was punched out, inoculated at the centre of plates and incubated at room temperature of $28 \pm 1^{\circ} \mathrm{C}$. As a control, the dishes were inoculated in distilled water-agar mix instead of solvent extracts-agar mix. Two (2) control plates were prepared for each solvent extracts. For positive control, no solvent extracts-agar mix or distilled water-agar mix was introduced into the plates. Growth measurement of the mycelia in diameter was done daily for seven days (Udo et al., 2006).

Phytochemical Screening of Plant Extracts: Phytochemical screening of the plant extracts was carried out at the Department of Biochemistry, University of Calabar, Nigeria using the methods of Sofowora (1984), Trease and Evans (1973) and Culei (1982).

\section{RESULTS}

Identification of Pathogens: The fungal pathogens isolated and identified from this study and used were Mucor mucedo and Trichoderma viride.

Phytochemical Screening: Phytochemical screening of Carica papaya and Azadirachta indica leaves in this study showed that they contain secondary metabolites like alkaloids, glycosides, flavonoids and polyphenols as presented in (Tables 1 and 2).

Antifungal Effect of Carica papaya and Azadirachta indica Extracts on Mycelia Growth of the Fungal Pathogens at the Different Concentrations: Results from percentage inhibition of the plant extracts on each fungus from this study showed that, at $10 \%$ and $20 \%$ concentrations, Carica papaya and Azadirachta indica extracts of methanol, ethanol, propanol, butanol, 
chloroform, acetone and the control distilled water had no significant effect on the mycelia growth of Trichoderma viride and Mucor mucedo after seven days observation period as shown in (Figures 1 -14). However, Carica papaya and Azadirachta indica extracts of butanol showed the most inhibition. At 30\% concentration, Carica papaya and Azadirachta indica Table 1. Phytochemical components of Carica papaya leaves.

\begin{tabular}{llccccc}
\hline S/N & Chemical constituent & Ethanol & Methanol & Acetone & Chloroform & Water \\
\hline 1. & Alkaloids & ++ & + & + & + & + \\
2. & Glycosides & + & + & + & + & + \\
3. & Saponins & + & - & + & + & + \\
4. & Tannins & - & + & - & - & - \\
5. & Flavonoids & + & ++ & +++ & + & + \\
6. & Reducing compounds & + & ++ & - & - & + \\
7. & Polyphenols & ++ & +++ & + & + & ++ \\
8. & Phlobatanins & + & + & + & - & - \\
9. & Anthra Quinine & - & + & + & - & - \\
10. & Hydroxymethyl Anthraquinine & - & - & + & - & - \\
\hline
\end{tabular}

Note: +++ (strongly present) ++ (Moderately present) + (Present) - (Absent)

Table 2. Phytochemical components of Azadirachta indica leaves.

\begin{tabular}{llccccc}
\hline S/N & Chemical constituent & Ethanol & Methanol & Acetone & Chloroform & Water \\
\hline 1. & Alkaloids & + & + & + & + & + \\
2. & Glycosides & + & + & + & + & + \\
3. & Saponins & - & - & + & - & + \\
4. & Tannins & - & + & - & - & - \\
5. & Flavonoids & + & + & ++ & + & + \\
6. & Reducing compounds & + & ++ & + & - & + \\
7. & Polyphenols & +++ & +++ & ++ & + & + \\
8. & Phlobatanins & - & - & - & + & + \\
9. & Anthra Quinine & + & - & + & - & - \\
10. & Hydroxymethyl Anthraquinine & - & + & + & - & - \\
\hline
\end{tabular}

Note: +++ (strongly present) ++ (Moderately present) + (Present) - (Absent)

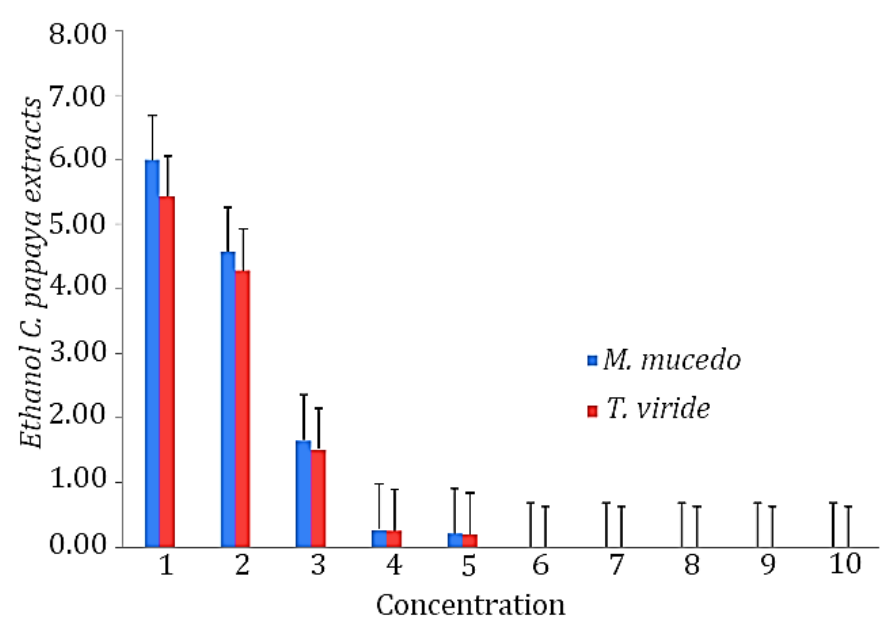

Figure 1. Effect of Carica papaya (ethanol) extract on mycelia growth of $M$. mucedo and $T$. viride at the different concentrations. extracts of ethanol and butanol had a slight significant effect on Mucor mucedo and Trichoderma viride. While at $40 \%$ concentration, Carica papaya extracts of propanol and butanol had a significant effect on Mucor mucedo. A. indica extract of butanol had the highest significant effect on Mucor mucedo and T. viride as shown in (Figures 1, 2, 8 and 9).

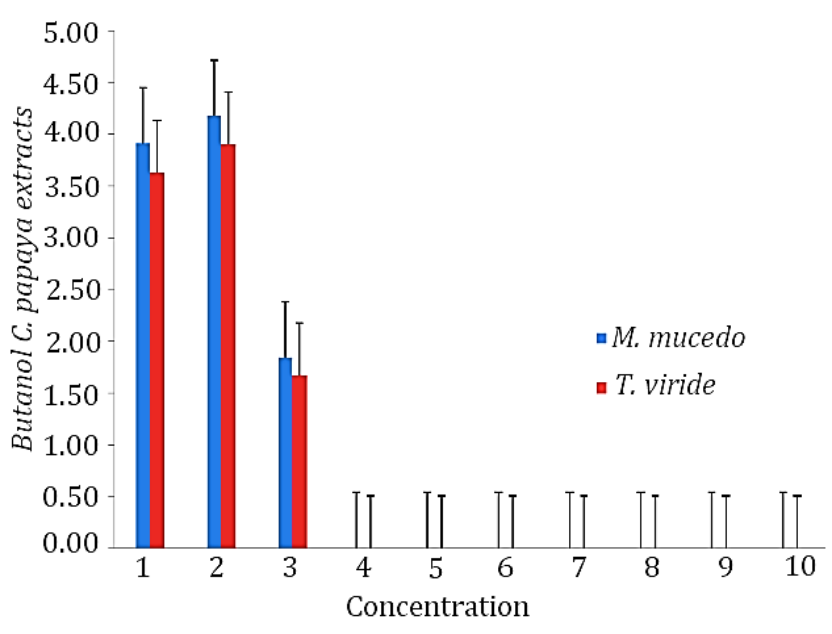

Figure 2. Effect of Carica papaya (butanol) extract on mycelia growth of $M$. mucedo and $T$. viride at the different concentrations. 
At $50 \%$ concentration, C. papaya extracts of propanol and butanol had a significant effect on M. mucedo, while a slight effect was observed with C. papaya extracts of ethanol and chloroform. C. papaya extracts of acetone and ethanol had a slight effect on T. viride. The control distilled water also had a slight effect on T. viride. A. indica extracts of butanol, methanol and ethanol had a slight effect on M. mucedo and T. viride as shown in (Figure 1, 2, 3, 4, 6, 7, 8, 9 and 12).

At $60 \%$ concentration, C. papaya extracts of ethanol, propanol and butanol had a significant effect on $\mathrm{M}$. mucedo and T. viride. The control distilled water and $\mathrm{C}$.

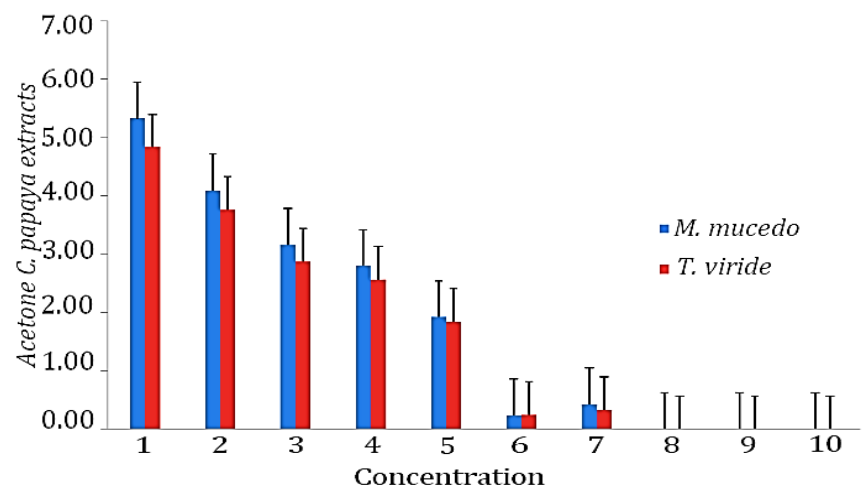

Figure 3. Effect of Carica papaya (Acetone) extract on mycelia growth of $M$. mucedo and $T$. viride at the different concentrations.

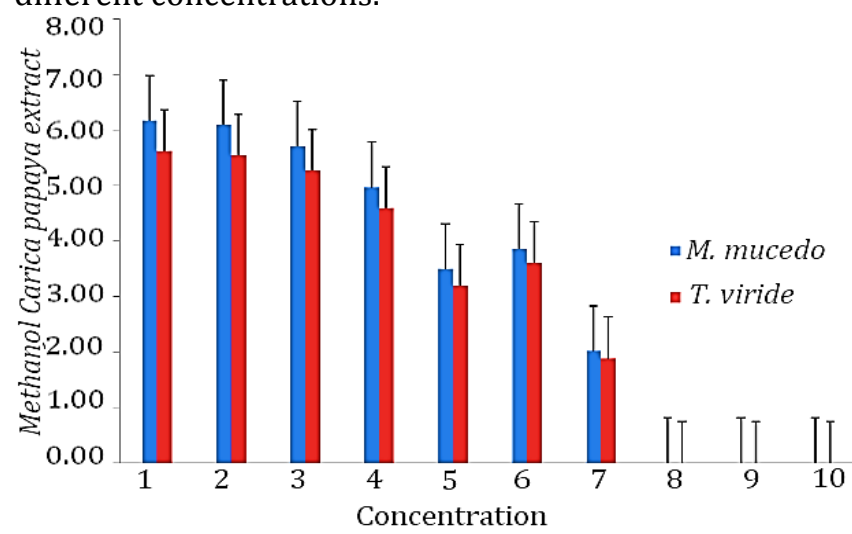

Figure 5. Effect of Carica papaya (Methanol) extract on mycelia growth of $M$. mucedo and $T$. viride at the different concentrations.

At 80 and $90 \%$ concentrations, C. papaya and A. indica extracts of methanol, ethanol, butanol, propanol, acetone and the control distilled water had a significant effect on M. mucedo and T. viride except at $80 \%$ concentration of C. papaya extracts of methanol and acetone which had a slight effect on T. viride. Also A. indica extract of propanol had a slight effect on T. viride as shown in (Figures 3, 5, 8, 9, 10, 12, 13 and 14). papaya extract of acetone had a slight effect on M. mucedo and T. viride. C. papaya extract of chloroform had no effect on the pathogens. While A. indica extracts of methanol and ethanol had a significant effect on $\mathrm{T}$. viride, but a slight effect on $\mathrm{M}$. mucedo. At $70 \%$ concentration, A. indica extracts of methanol, butanol, and acetone had a significant effect on M. mucedo and T. viride. While C. papaya extracts of ethanol, propanol and butanol had a significant effect on M. mucedo and T. viride. C. papaya extract of methanol had a significant effect on M. mucedo but not on T. viride as shown in (Figures 1, 2, 3, 4, 6, 7, 8, 9, 10 and 12).

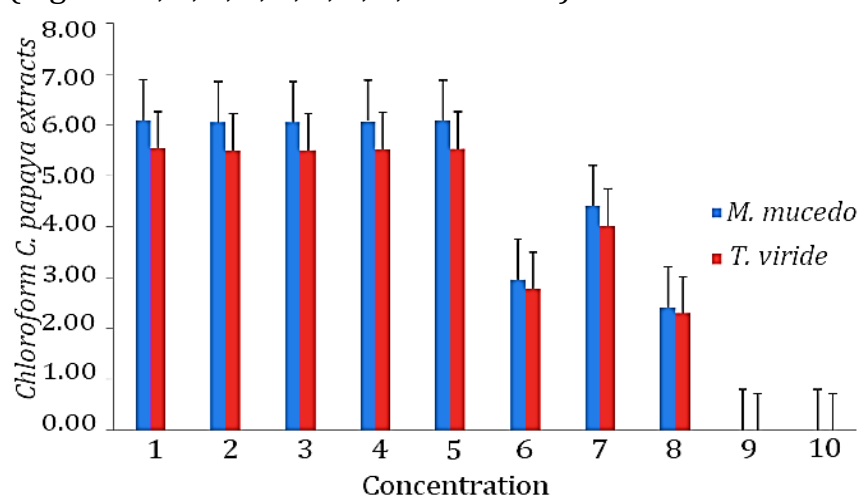

Figure 4. Effect of Carica papaya (Chloroform) extract on mycelia growth of $M$. mucedo and $T$. viride at the different concentrations.

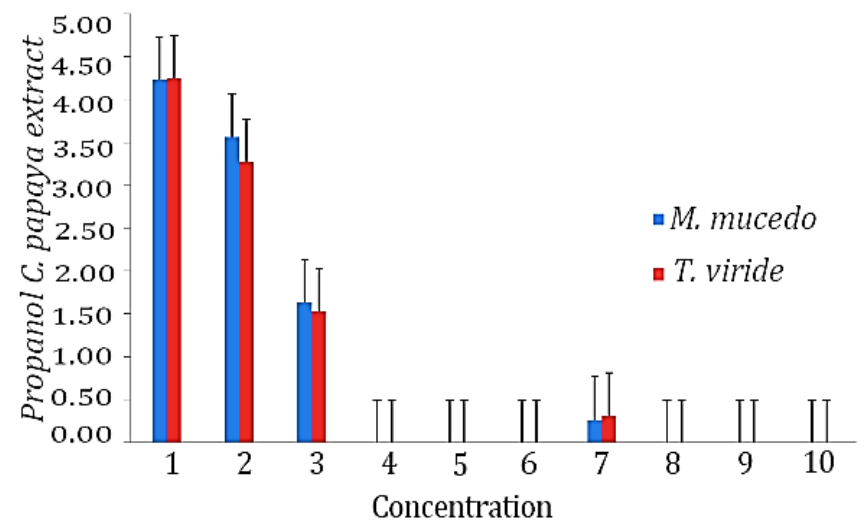

Figure 6. Effect of Carica papaya (Propanol) extract on mycelia growth of $M$. mucedo and $T$. viride at the different concentrations.

At $100 \%$ concentration, C. papaya extracts of the different solvents had a significant effect on M. mucedo and T. viride. The control distilled water had a significant effect on $\mathrm{M}$. mucedo but not on T. viride. While A. indica extracts of methanol, ethanol, propanol, butanol and acetone had a significant effect on the fungal pathogens except for chloroform and the control distilled water as shown in (Figure 1-14). 


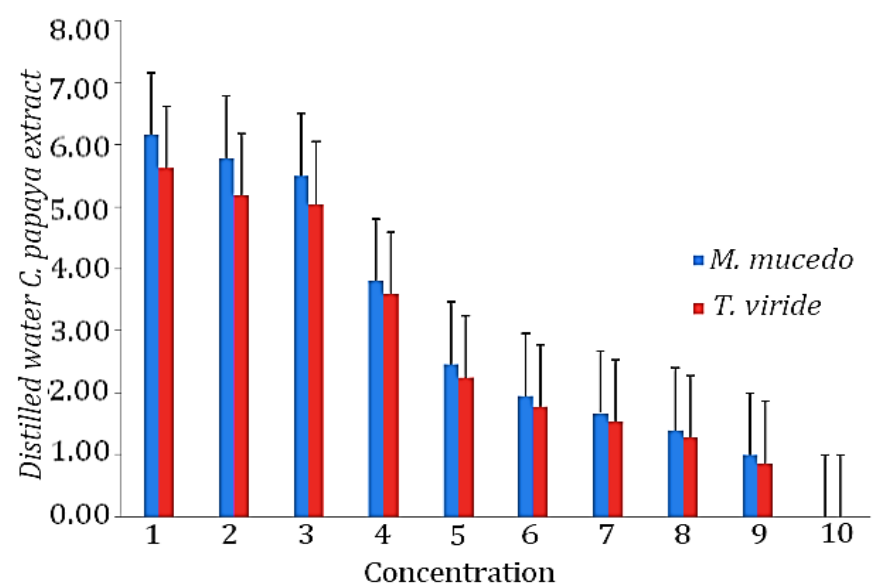

Figure 7. Effect of Carica papaya (Distilled water) extract on mycelia growth of $M$. mucedo and $T$. viride at the different concentrations.

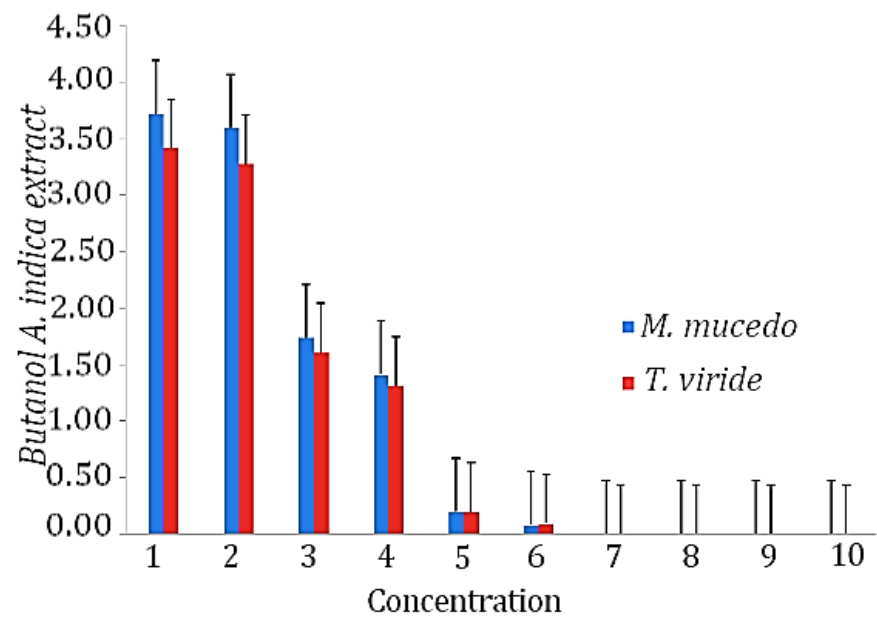

Figure 9: Effect of Azadirachta indica (Butanol) extract on mycelia growth of $M$. mucedo and $T$. viride at the different concentrations.

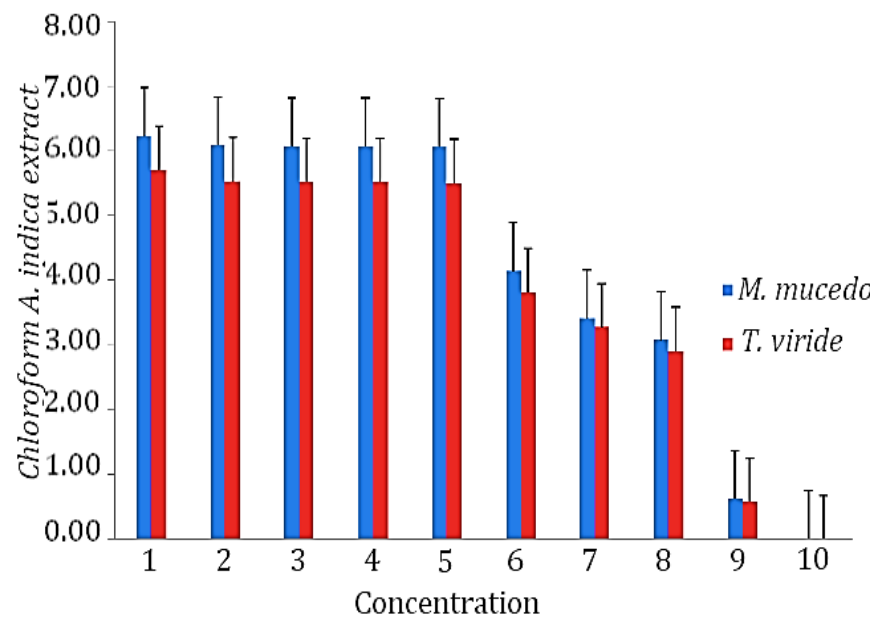

Figure 11: Effect of Azadirachta indica (Chloroform) extract on mycelia growth of $M$. mucedo and $T$. viride at the different concentrations.

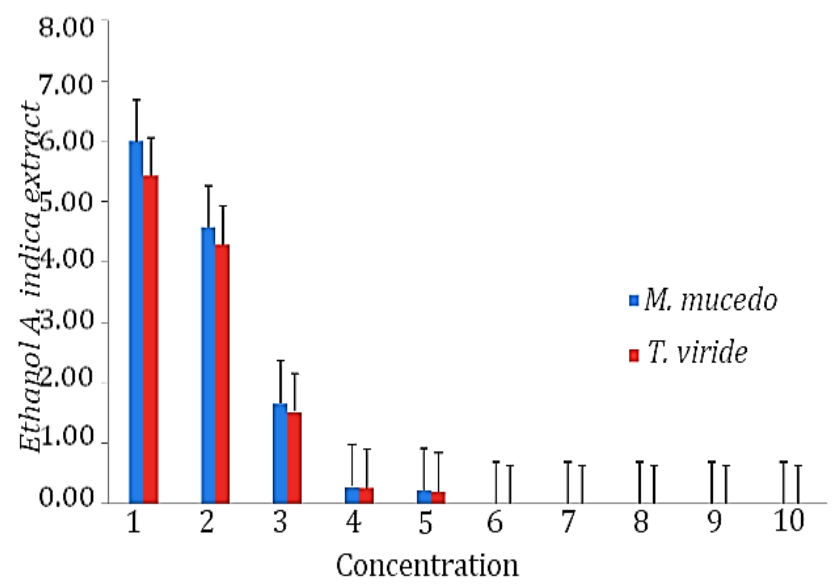

Figure 8. Effect of Azadirachta indica (Ethanol) extract on mycelia growth of $M$. mucedo and T. viride at the different concentrations.

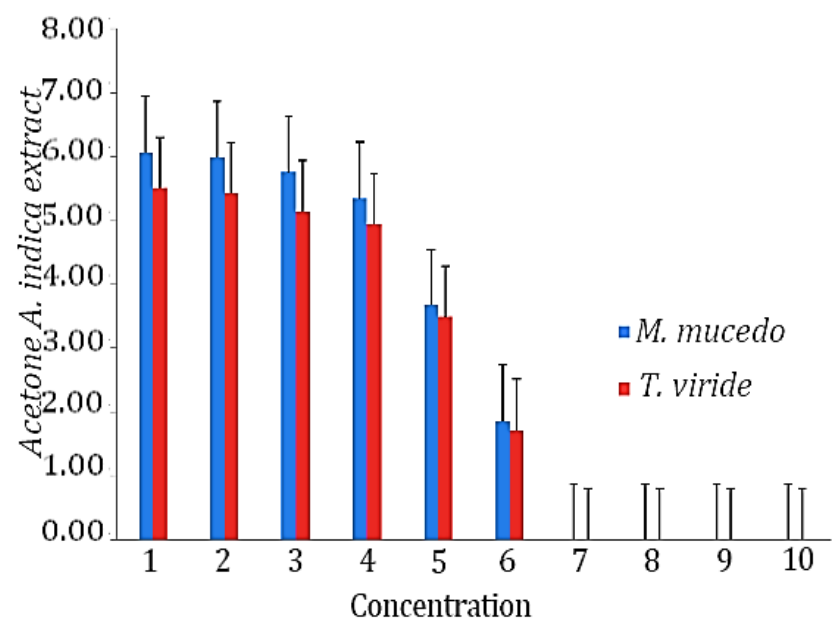

Figure 10: Effect of Azadirachta indica (Acetone) extract on mycelia growth of M. mucedo and T. viride at the different concentrations.

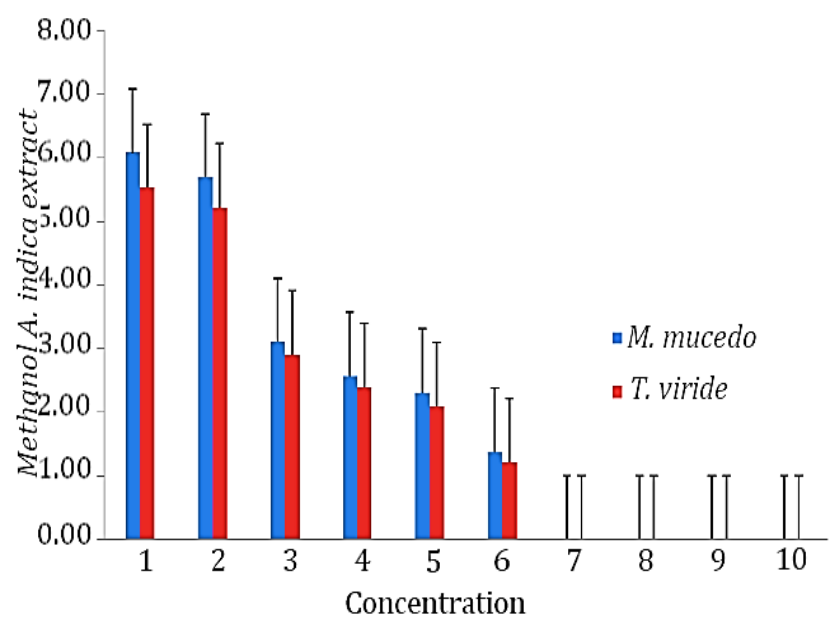

Figure 12: Effect of Azadirachta indica (Methanol) extract on mycelia growth of M. mucedo and T. viride at the different concentrations. 


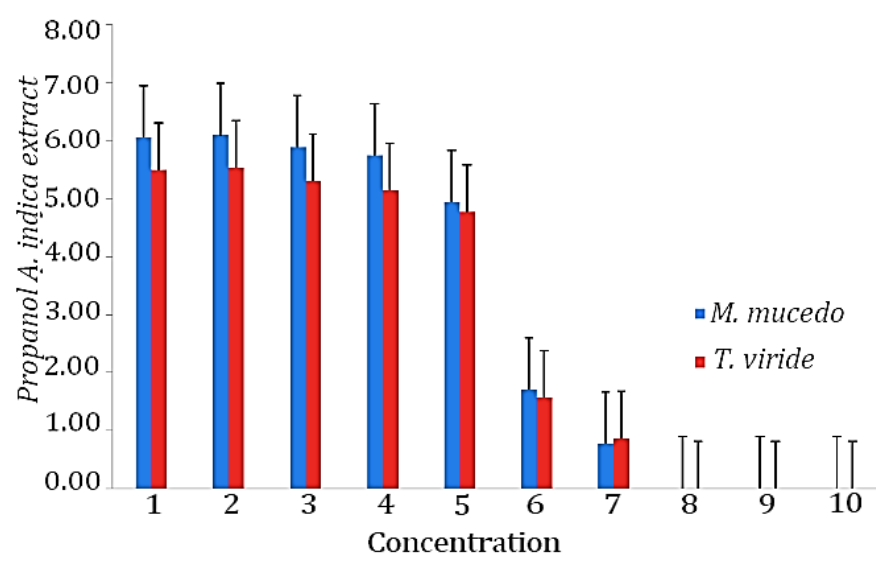

Figure 13: Effect of Azadirachta indica (Propanol) extract on mycelia growth of $M$. mucedo and T. viride at the different concentrations.

\section{DISCUSSION}

Phytochemical screening of extracts of $C$. papaya from the different solvents showed that there was no tannin and hydroxymethyl anthraquinine. Flavonoids and polyphenols were in excess in acetone and methanol extracts respectively. For $A$. indica, polyphenols were only found in excess in ethanol and methanol extracts, these results are similar to those of Mbadianya et al., (2013) who reported the presence of flavonoids, alkaloids, glycosides and polyphenols in methanolic and ethanolic leaf extracts of C. papaya and A. indica. In this study, a general trend of increased antifungal activities was observed with a corresponding increase in the concentrations of the extract solvents of Azadirachta indica and Carica papaya. The fungal pathogens were completely inhibited at $80 \%, 90 \%$ and $100 \%$ concentrations this disagrees with that of Olahan and Amadi (2006) who reported the fungicidal effect of aqueous and ethanolic leaf extracts of C. papaya against Fusarium verticilliodes at different concentrations of 10 , 30 and $50 \%$. Both extracts retarded the radial growth of $\mathrm{F}$. verticilliodes with ethanolic extract having a greater fungistatic effect at the different concentrations tested. The antifungal effect of the plant extracts however declined as the concentration reduced to $10 \%$, this is in conformity with the work of Onifade (2000) who reported a general trend of increased antifungal activity with a corresponding increase in concentration of aqueous A. indica extract on Colletotrichum lindemuthianum. In this study, we observed that C. papaya and A. indica extract of chloroform had the least effect on the potency of the plant extracts on the fungal pathogens, while C. papaya and A. indica extracts of butanol was the most effective. The

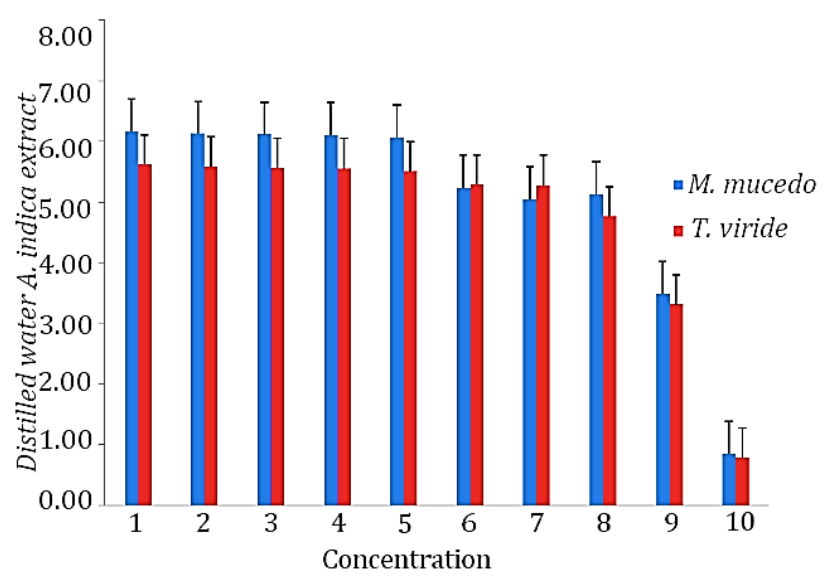

Figure 14: Effect of Azadirachta indica (Distilled water) extract on mycelia growth of M. mucedo and T. viride at the different concentrations.

potency of these plant extracts could be due to increase in concentration as proposed by Maragathavalli et al., (2012) who observed that the percentage inhibition of an isolated fungus increased with a corresponding increase in the concentration of the extract. Also the inhibition of the growth of the fungus is as a result of the phytochemical contained in the extracts as reported by Udo et al., (2006). We also observed that Azadirachta indica extracts was less effective in the control of the fungal pathogens as compared to Carica papaya extracts at lower concentrations; this may be due to the fact that the phytochemicals contained in C. papaya extracts were stronger and effective than those of A. indica. This finding agrees with that of Mahesh and Satish (2008) on antimicrobial activity of some medicinal plants on fungal pathogens.

\section{CONCLUSION}

This study showed that Carica papaya extracts was more effective in inhibiting the mycelia growth of both Trichoderma viride and Mucor mucedo than those of Azadirachta indica. The inhibition increased with the increase in concentrations of the extracts for both plants. C. papaya and A. indica extracts of butanol were found to be the most effective in inhibiting the growth of both fungal pathogens while chloroform was least effective. Therefore, Carica papaya and Azadirachta indica extracts of butanol at higher concentrations is highly recommended to be used as spray for the control of the fungal diseases of the Gmelina arborea seedlings.

\section{REFERENCES}

Adegbehin, J. O, J. O. Abayomi and L. B. Nwaigbo. 1988. Gmelina arborea in Nigeria. Com. For. Rev. 67(2): 159-166. 
Alexopolous, C. J and C. W. Mins. 1989. Introductory Mycology, London, John Wiley and sons. Pp 224-228.

Barnett, H. L and B. B. Hunter. 1998. Illustrated genera of imperfect fungi (4th edition), St Paul Minnesota, The Amer. Phytopathol. Soc. Pre. USA.

Culei, K. W. 1982. Therapeutic action of medicinal plants on fungi. Microb. Meth. 6: 35-40.

Duke, J. A. 2002. Gmelina arborea Roxb. Purdue University, Centre for New Crops and plant products.

http:www.hot.purden.edu/newcrop/dukeenergy/Gmelinaarborea.html.

Dvorak, W. S. 2003. World view of Gmelina arborea opportunities and challenges. In recent advances with Gmelina arborea (eds. W .S. Dvorak, G. R. Hvdge, W.C. Woodbridge and J.C. Romeo) North Carolina State University, Raleigh, NC. USA.

Epinoza, J. A. 2003. Site selection, site preparation, and weed control of Gmelina arborea. In recent advances with Gmelina arborea (eds. W .S. Dvorak, G. R. Hvdge, W. C. Woodbridge and J.C. Romeo) North Carolina State University, Raleigh, NC. USA.

Lauridsen, E. B and N. Kjaer. 2002. Provenance research in Gmelina arborea Lin. Roxb. A summary of results from three decades of research and a discussion of how to use them. Inter. For. Rev. 4(1): 15.

Mahesh, B. and S. Satish. 2008. Antimicrobial activity of some important medicinal plants against plant and human pathogens. Wor. J. of Agricul. Sci. 4(5): 839-843.

Maragathavalli, S., S. Brinda, N. S. Kaviyarasi, B. Annadurai and S. K. Gangwar. 2012. "Antimicrobial Activity of in leaf extracts of Neem", Inter. J. of Sci. and Nat. 3: 110-113.

Mbadianya, J. I., B. C. Echezona, K. I. Ugwuoke and R. C. Wokocha. 2013. Phytochemical constituents of some medicinal plants. Int. J. of Sci. and Res. (IJSR) Volume 2, Issue 4. ISSN: 2319-7064.

Olahan, G. S and J. E. Amadi. 2006. Fungicidal effect of Pawpaw (Carica papaya L.) leaf extracts on Fusarium verticilliodes. Afric. Sci. Vol.7, No.1.

Onifade, A. U. 2000. Anti-fungal effect of Azadirachta indica A. juss extracts on Colletotrichum lindemuthianum. Glo. J. of pure and Appl. Sci.vol.6, No.3: 425-428.

Sofowora, A. 1984. Medicinal plants and fractional medicine in Africa. New York, John Wiley and Sons Incorporated. 32p.

Trease, G. E and W. C. Evans. 1978. A textbook of pharmacognosy, $11^{\text {th }}$ Edition. London, Bailliere Teindall, Pp. 56-58.

Udo, S. E, B. E. Madunagu, E. J. Umana, A. A. Markson and I. Takon. 2006. The efficacy of extracts from four oil seeds and an oil fruit as antimicrobial agents in comparison with known antibiotics. J. of Agricul. For. and the Soc. Sci. 4 (2): 119-125. 